\title{
Accuracy of Infrared Forehead Skin Thermometry in Newborns - A Comparison with Digital Axillary and Rectal Mercury Thermometers
}

\author{
Rita Hajela ${ }^{1}$ \\ ${ }^{1}$ Department of Paediatrics, Maharishi Markandeshwar Medical College and Hospital, \\ Kumahatti, Solan, Himachal Pradesh, India.
}

ABSTRACT

\section{BACKGROUND}

Temperature is an important vital sign especially in neonates. Providing thermal comfort to baby is part of essential newborn care. The ideal temperature measurement method should be accurate, safe, noninvasive, time efficient, easy to operate and non-disturbing to baby. Mercury thermometers have been banned; rectal measurements are hazardous. Digital axillary thermometers although widely accepted, also have their limitations and sometimes produce questionable results in newborn. Infrared forehead thermometry is a promising tool with controversial results; hence this newer technology needs to be repeatedly tested and validated.

\section{METHODS}

This is a prospective comparative study conducted in a tertiary care hospital situated in the hilly areas of Solan district of Himachal Pradesh. We simultaneously recorded three temperatures at three sites by different methods and different thermometers Forehead skin temperature was recorded in apparently normal newborns by INNOVA infrared thermometer and axillary temperature was recorded by digital thermometer and rectal temperature was recorded by mercury in glass thermometer.

\section{RESULTS}

260 newborns were included in the study. Data was analysed for correlation by Pearson $r$ coefficient and for agreement by Bland-Altman method. A strong correlation was found between infrared forehead temperature and digital axillary temperature with a Pearson $r$ of 0.826 and 0.801 between infrared forehead temperature and rectal mercury thermometer. Bland-Altman analysis of difference produced a mean difference of 0.49 and level of agreement of -1.67 and +2.65 when axillary digital and infrared forehead thermometry measurements were compared. Mean difference of 0.15 with level of agreement as -2.09 and +2.40 were obtained when rectal mercury and infrared forehead temperatures were compared.

\section{CONCLUSIONS}

Although a strong correlation of infrared skin thermometry was found with both axillary digital and rectal mercury temperature measurements. The level of agreement has a wide variation which is not clinically acceptable hence infrared forehead skin thermometry is not recommended for use in newborns.

\section{KEY WORDS}

Newborn, infrared Thermometer, Digital Thermometer, Rectal Thermometer, Mercury Thermometer, Temperature, Hypothermia, Fever
Corresponding Author:

Dr. Rita Hajela,

Associate Professor,

Department of Paediatrics,

Maharishi Markandeshwar Medical

College and Hospital, Kumarhatti,

Solan-173229, Himachal Pradesh, India.

E-mail: hajelarita@gmail.com

DOI: $10.14260 /$ jemds/2020/124

Financial or Other Competing Interests: None.

How to Cite This Article:

Hajela R. Accuracy of infrared forehead skin thermometry in newborns- a comparison with digital axillary and rectal mercury thermometers. J. Evolution Med. Dent. Sci.2020;9(08):555-561, DOI: $10.14260 /$ jemds/2020/124

Submission 05-12-2019,

Peer Review 30-01-2020,

Acceptance 04-02-2020,

Published 24-02-2020. 


\section{BACKGROUND}

It is estimated that $15 \%$ of newborn babies develop hypothermia at birth in developing countries.[1] Instead of $\mathrm{ABC}, \mathrm{TABC}$ is the dictum of newborn care, both in hospital as well as at home. After birth skin and core temperature of baby falls by $0.3^{\circ} \mathrm{C}$ and $0.1^{\circ} \mathrm{C}$ per minute respectively, equivalent to a heat loss of $200 \mathrm{kcal} / \mathrm{kg} /$ minute. The baby can quickly become hypothermic unnoticed if due care is not taken at this time. Therefore, temperature monitoring of newborn is part of essential newborn care. ${ }^{[2,3]}$ Cold stress or Hypothermia triggers a chain of events leading to increased morbidity and mortality, not only at this time but later also during sponging, bathing, changing of clothes, or by remaining in contact with wet diaper for prolonged period, inadequate clothing or inadequate room temperature especially in winters and in hill areas. On the other hand fever or hyperthermia is also a manifestation of thermal stress to baby, as well as a sign of serious bacterial infection or dehydration or excessive clothing etc.[4] Thermal stress due to hyperthermia is considered a hidden cause of death in ELBW babies and is considered to be associated with increased mortality both per se and during rapid rewarming following hypothermia.[5] Sensitization of caregivers towards thermal care of newborn is an important part of newborn care as baby becomes hot or cold too quickly before one gets alert to the situation and therefore frequent body temperature measurement may become necessary.

Rectal thermometry has remained the gold standard for its accuracy and sensitivity since long but is undesired as a screening tool as we need to remove clothes and there is risk of rectal perforation, chance of introducing infection and is inconvenient both for baby and for caretaker. Infrared skin thermometer has come up as a promising tool and has been suggested as a good alternative for newborns. [6]

Mercury glass thermometers were the usual choice till Minamata diseases were discovered and mercury fell out of favour because of fear of spillage, subsequent environmental pollution and mercury poisoning. Both in hospital and home settings, mercury spillage is fairly common due to breaking of glass thermometer. Safe disposable of mercury is very difficult, physical contact results in quick absorption of mercury through skin and otherwise it readily turns into vapour at room temperature and on inhalation gets absorbed into bloodstream leading to symptoms of nausea, tremors, blurred vision, fever, convulsions etc. Given its risks west has already stopped its use and India is in process of doing so following the Minamata convention in 2013.[7] United nations Environmental programme (UNEP) Minamata convention on mercury comes into force globally in 2020 and India is a signatory to it. Mercury thermometers have been largely replaced by digital thermometers, in the next generation came the infrared thermometers. Accuracy, sensitivity, specificity, availability, affordability, durability, reproducibility, time consumed, training time, ease of handling, practicability are the parameters which should be fulfilled by any newer devise which is replacing the gold standard. Something new is usually tested analysed and recommended or not recommended globally, first in adults than in paediatric population and lastly in newborns. Infrared thermometers are recommended for use in adults and children but have not been recommended for use in newborns by manufacturer, whereas newborn is the most vulnerable population for variations in body temperature. The studies done so far have met with conflicting reports. Therefore, we explored its possible use in newborn and compared our results with digital axillary thermometer and mercury in glass rectal thermometer.

\section{METHODS}

A prospective cross-sectional study done on newborns in Postpartum wards of Maharishi Markandeshwar Medical college and Hospital, Solan. The study was approved by Institutional Ethical Committee. Informed consent was taken for recording of newborn temperature by different methods from mother of the baby. 260 babies born in our institute from 01. 07. 2018 to 30.06. 2019 were included in the study. Comparative thermometry process was done once, in each recruited baby who met the inclusion criteria, while the baby was roomed in with mother and was being handled by parents. Age of baby was recorded in days. No recording was made for babies who had not completed 12 hours of age.

Temperatures were recorded by standard technique sequentially and the task was completed between $10 \mathrm{AM}$ to 11 AM to minimize the effect diurnal variation. The order of recording was as follows, first baby's cap was pulled away pulling just enough to expose the area where skin thermometer needed to be placed, if it was covering the forehead and temporal areas also because putting up a larger cap is often found in our Indian scenario, but cap was never removed. First forehead temperature was recorded by infrared thermometer in center than on both sides over temporal region. Thus 3 readings were recorded and the lowest one was taken into account. Just after this axillary digital thermometer was put following standard technique in left axilla and while axillary thermometer was in place, rectal thermometer was also put. Baby was kept supine on bed throughout the procedure. Temperature was recorded just after beep from axillary digital thermometer. Rectal temperature was recorded after keeping rectal thermometer in place for 3 minutes following standard technique.

\section{Inclusion Criteria}

- Newborns who were apparently healthy, and are being looked after by mother and family at the time of study.

- Newborn delivered after $\geq 34$ completed weeks of gestation.

- Newborn with birth weight of $\geq 1750$ gm.

\section{Exclusion Criteria}

- $\quad$ Birth weight $<1750$ gm.

- Gestation $<34$ weeks.

- Congenital anomaly.

- NICU admission.

- Any other illness noted before thermometry.

\section{Equipment}

Temperature was recorded by the same person daily to avoid inter operator difference.

- Forehead skin temperatures were recorded by Innovo Dual mode infrared thermometer (INV EF 100 model). 
- Axillary temperature was recorded using Dr Gene digital thermometer.

- Rectal temperature was recorded by Doctor RANA mercury in glass rectal thermometer.

\section{Statistical Analysis}

Analyze -it software ultimate version 2019 (32 bit) for Windows was used for Statistical analysis. Data was analyzed for correlation by Pearson correlation coefficient between digital and infrared thermometry as well as between mercury and infrared thermometry and the results obtained are given.

\section{RESULTS}

\begin{tabular}{|c|c|c|c|c|c|c|c|c|}
\hline Age & $\begin{array}{c}\text { Day } 1 \\
(12-24 \\
\text { hrs })\end{array}$ & $\begin{array}{c}\text { Day } 2 \\
(24-48 \\
\text { hrs })\end{array}$ & $\begin{array}{c}\text { Day } 3 \\
(48-72 \\
\text { hrs })\end{array}$ & $\begin{array}{c}\text { Day 4 } \\
\text { (72-96 } \\
\text { hrs) }\end{array}$ & $\begin{array}{c}\text { Day } 5 \\
(96-120 \\
\text { hrs }) \\
\end{array}$ & \begin{tabular}{|c|} 
Day 6 \\
$(120-144$ \\
hrs $)$ \\
\end{tabular} & \begin{tabular}{|c|} 
Day 7 \\
(144- \\
178 hrs) \\
\end{tabular} & $\begin{array}{c}>7 \\
\text { days }\end{array}$ \\
\hline $\mathrm{N}$ & 61 & 85 & 58 & 21 & 12 & 8 & 6 & 9 \\
\hline$\%$ & 23.46 & 32.69 & 22.30 & 8.07 & 4.61 & 3.07 & 2.31 & 3.46 \\
\hline & \multicolumn{3}{|c|}{$204(78.46 \%)$} & \multicolumn{5}{|c|}{$56(21.54 \%)$} \\
\hline
\end{tabular}

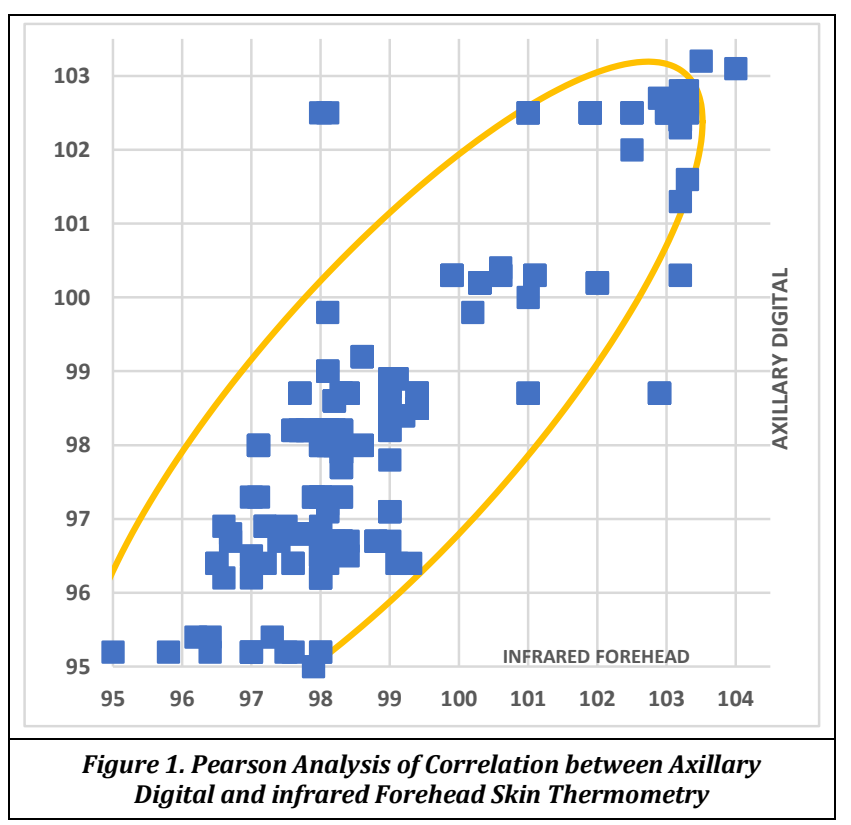

\begin{tabular}{|c|c|c|}
\hline $\mathrm{N}$ & 260 & \\
\hline \multicolumn{2}{|c|}{ Correlation } & \\
\hline Pearson's r & 0.826 & \\
\hline Fisher 95\% CI & 0.783 & to 0.861 \\
\hline Hypothesized value & 0 & \\
\hline t approximation & 23.52 & \\
\hline DF & 258 & \\
\hline p-value & $<0.0001$ & \\
\hline
\end{tabular}

Table 1. Pearson Analysis of Correlation between Axillary Digital and infrared Forehead Skin Thermometry

H0: $\rho=0$. The correlation coefficient $\rho$ of the bivariate population is equal to 0 . H1: $\rho \neq 0$. The correlation coefficient $\rho$ of the bivariate population is not equal to 0 .

\begin{tabular}{|c|c|c|}
\hline $\mathrm{N}$ & 260 & \\
\hline \multicolumn{2}{|c|}{ Correlation } \\
\hline Pearson's r & 0.801 & \\
\hline Fisher 95\% CI & 0.753 & to 0.841 \\
\hline Hypothesized value & & \\
\hline t approximation & 0 & \\
\hline $\mathrm{DF}$ & 21.49 & \\
\hline p-value & 258 & \\
\hline $\begin{array}{c}\text { Table 2. Pearson Analysis of Correlation between Rectal Mercury and } \\
\text { infrared Forehead Skin Thermometry }\end{array}$ \\
\hline
\end{tabular}

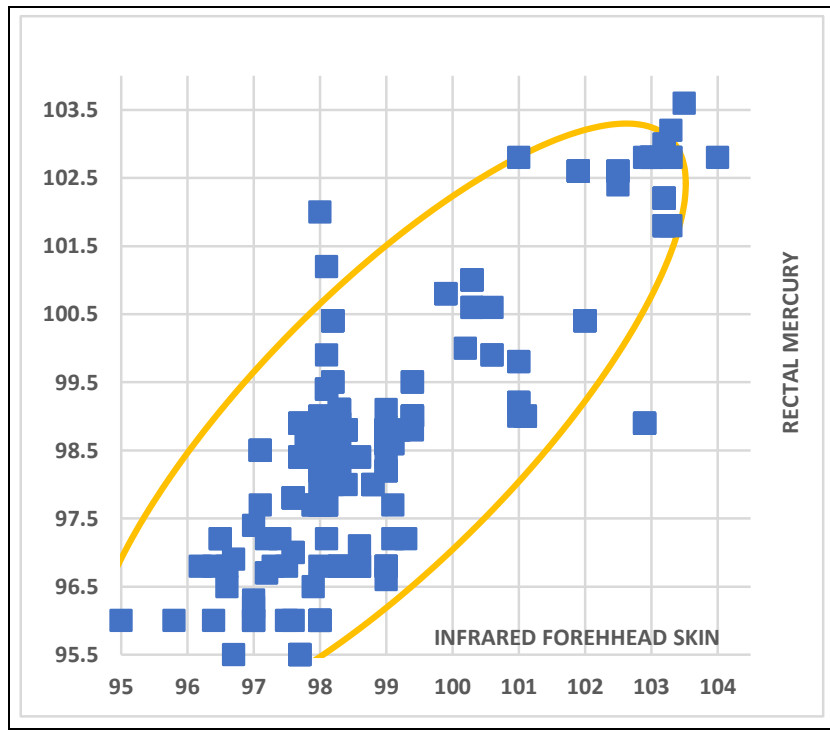

Figure 2. Pearson Analysis of Correlation between Rectal Mercury and infrared Forehead Skin Thermometry

\begin{tabular}{|c|c|c|c|c|}
\hline Difference Plot & & & & \\
\hline \multirow[t]{2}{*}{$\mathbf{N}$} & 260 & & & \\
\hline & Minimum & Maximum & & \\
\hline Axil L & 95.00 & 103.20 & & \\
\hline Head C 3 & 95.00 & 104.00 & & \\
\hline$($ Axil L + Head C 3) / 2 & 95.10 & 103.55 & & \\
\hline \multicolumn{5}{|l|}{ Fit Differences } \\
\hline Parameter & Estimate & \multicolumn{2}{|c|}{$95 \% \mathrm{CI}$} & SE \\
\hline Mean difference & 0.49 & 0.352 & to 0.621 & 0.068 \\
\hline 95\% Lower LoA & -1.67 & -1.905 & to -1.444 & 0.117 \\
\hline 95\% Upper LoA & 2.65 & 2.417 & to 2.878 & 0.117 \\
\hline SD & 1.10 & & & \\
\hline \multicolumn{5}{|c|}{$\begin{array}{c}\text { Table 3. Bland Altman Comparison Analysis of Axillary Digital } \\
\text { and infrared Forehead Skin Thermometry }\end{array}$} \\
\hline
\end{tabular}

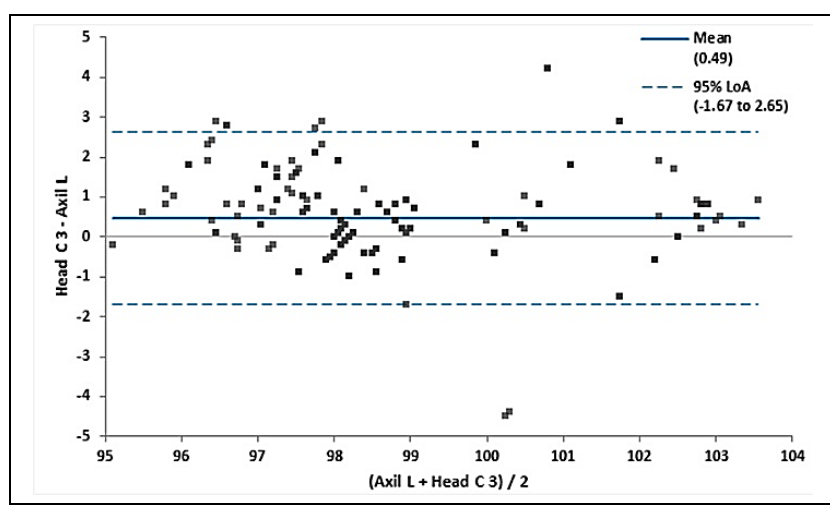

Figure 3. Bland Altman Comparison Analysis of Axillary Digital and infrared Forehead Skin Thermometry

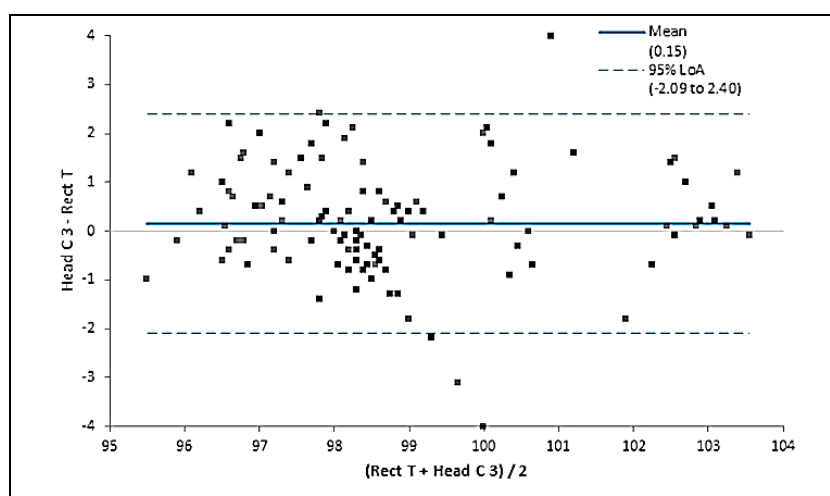

Figure 4. Bland Altman Comparison Analysis of Rectal Mercury and infrared Forehead Skin Thermometry 


\begin{tabular}{|c|c|c|c|c|}
\hline $\mathrm{N}$ & 260 & & & \\
\hline & Minimum & Maximum & & \\
\hline Rect T & 95.50 & 103.60 & & \\
\hline Head C 3 & 95.00 & 104.00 & & \\
\hline (Rect T + Head C 3) / & 95.50 & 103.55 & & \\
\hline Fit Differences & & & & \\
\hline Parameter & Estimate & \multicolumn{2}{|c|}{$95 \%$ CI } & SE \\
\hline Mean difference & 0.15 & 0.014 & to 0.294 & 0.071 \\
\hline 95\% Lower LoA & -2.09 & -2.335 & to -1.855 & 0.122 \\
\hline 95\% Upper LoA & 2.40 & 2.164 & to 2.643 & 0.122 \\
\hline SD & 1.15 & & & \\
\hline Table 4. Bland Altman Comparison Analysis of Rectal Mercury \\
and infrared Forehead Skin Thermometry \\
\hline
\end{tabular}

The study included a total of 260 newborn subjects, with almost equal distribution into male 131 (50.38\%) and female 129 (49.62\%) sex. Regarding mode of delivery 166 subjects (63.85\%) were born by vaginal delivery and $94(36.15 \%)$ by caesarean section. $22(8.46 \%)$ newborns were preterms with gestation varying from 34 to 36 completed weeks, rest of the $238(91.54 \%)$ newborns were term with gestation varying from 37 to 41 completed weeks. There was no newborn beyond that gestation, hence no post-term subject was part of our study. Birth weight wise 64 (24.61\%) newborns were low birth weight (LBW) including both Small for gestational age (SGA/IUGR) and preterm babies with weight varying from 1760 to 2499 gram. We had only one large for gestational age (LGA) subject with birth weight of $>4000$ gram. All other babies were of normal birth weight which varied from $2500 \mathrm{~g}$ to 3999 grams. Mean birth weight was 2774 gram and median as 2765 grams, largest weight being $4140 \mathrm{~g}$. The age of baby at the time of taking temperature measurement varied from day one to day 26 but it was mainly clustered within early neonatal period of seven days and only $3.46 \%$ recordings were outside seven days window. Maximum readings $(78.46 \%)$ were taken within first 72 hours of life which is the most crucial time of physiological adaptation for baby. (Table 1)

Minimum temperature recorded was 95.0 by axillary method and maximum as 103.2. Minimum temperature recorded by infrared forehead thermometry was also 95.0 while maximum was 103.6. Minimum and Maximum temperatures recorded by rectal mercury thermometer were 95.5 and 103.6 respectively. The mean temperature by digital thermometer in left axilla was 98.52 and medians 98.2. Mean temperature recorded by rectal mercury in glass rectal thermometer was 98.86 and median as 98.6 while mean temperature by infrared thermometer on forehead was 99.1 and median as 98.3. The results showed a Pearson $r$ of 0.826 between digital thermometer readings and infrared forehead thermometer reading which is more than 0.7 suggesting a strong correlation between the two. (Figure 1) When we compared mercury rectal thermometer readings, which is considered the gold standard and infrared forehead thermometer readings Pearson $r$ value was 0.801 which is also more than 0.7 again suggesting a strong correlation between the two with inference that infrared forehead skin thermometry is a good alternative to digital axillary thermometry and mercury glass rectal thermometry. (Figure 2).
Difference analysis between different techniques was done by Standard Bland Altman method and results are given in Figure 3-4. The mean difference obtained between Axillary digital and infrared forehead thermometer was obtained as 0.49 with level of agreement as -1.67 and +2.65 , suggesting that they do not agree well. The mean difference obtained between Rectal mercury and infrared thermometer was as 0.15 with level of agreement as -2.09 and +2.40 . Suggesting that they do not agree well and cannot be used interchangeably.

\section{DISCUSSION}

American academy of Pediatrics and American congress of obstetricians and gynecologists recommends obtaining temperature in newborn via axilla, therefore we obtained axillary temperature for comparison. However Rectal thermometry by mercury thermometer has served as a gold Standard for decades therefore we also recorded time tested rectal temperature by mercury thermometer for comparison. The most widely accepted definition of normal body temperature is $98.6^{\circ} \mathrm{F}\left(37^{\circ} \mathrm{C}\right)$ which depended on studies performed by Wunderlich's in $19^{\text {th }}$ century on axillary temperatures of several million measurements on 25000 individuals. Mackowiack in more recent studies have found mean oral temperatures in adults to be $98.2^{\circ} \mathrm{F}$ with upper limit of normal as $98.9^{\circ} \mathrm{F}$ at 6 A.M. and $99.9^{\circ} \mathrm{F}$ at 4 P.M. with a variation of $1^{\circ} \mathrm{F}$, the nadir occurring in early morning hours and peak in late afternoon. Apart from circadian rhythm body temperature is affected by numerous other physiological factors, like after exercise \& in post prandial state body temperature increases, in women it is also affected by phase of menstrual cycle.

General public and Clinicians alike often refer to body temperature, the implication that a single number can represent the thermal state of entire body is inaccurate. Depending upon the site of measurement body temperature may vary by $1^{\circ} \mathrm{C}$ or $1.8^{\circ} \mathrm{F} / 2^{\circ} \mathrm{F}$. (8) These regional variations in temperature do not have a fixed relationship to each other. Axillary temperatures are consistently lower than rectal temperatures, the absolute difference between the two varies greatly. Clinicians are most interested in core body temperature i. e. internal organs of head and trunk. Under normal circumstances core temperature is higher than the temperature of more superficial tissues such as skin, even within these two anatomic regions temperature gradients exist. Therefore, we must keep in mind all these factors while interpreting any data of thermometry.

Harrisons text book defines a normal body temperature in $18-40$ years of age as mean oral temperature as $36.8 \pm 4^{\circ} \mathrm{C}$ or $98.2 \pm 7^{\circ} \mathrm{F}$ with low levels at 6 A.M. and higher levels at 4-6 P.M., with maximal normal as $98.9^{\circ} \mathrm{F}$ at 6 A.M. and maximum $99.9^{\circ} \mathrm{F}$ at 4 P.M. Normal daily temperature variation is typically $0.9^{\circ} \mathrm{F}$ or $0.5^{\circ} \mathrm{C}$. [9] Further it is stated that that even today, there is no universally accepted definition of fever especially for children and more so for newborn. Craig defined neonatal pyrexia as a rectal temperature $>37.4^{\circ} \mathrm{C}$ or $99.4^{\circ} \mathrm{F}$, other investigators accept temperatures up to $37.8^{\circ} \mathrm{C}$ as normal.[10] Nelson textbook of paediatrics defines normal temperature range for children as $97.9-100.2^{\circ} \mathrm{F}(36.6-37.9$ 
${ }^{\circ} \mathrm{C}$ ) depending upon Rectal readings. It also defines fever as a rectal temperature of $\geq 100.4^{\circ} \mathrm{F}\left(38^{\circ} \mathrm{C}\right)$ as fever.[11] We took the same readings for rectal temperature as reference values for hypo or hyperthermia/fever. National neonatology forum for Indian scenario defines temperature lower than normal or hypothermia as newborn axillary temperature $<36.5^{\circ} \mathrm{C}$ or $97.7^{\circ} \mathrm{F}$ and axillary temperature of $>37.5^{\circ} \mathrm{C}$ or $99.5^{\circ} \mathrm{F}$ as hyperthermia.[12] We took these reference ranges for axillary temperature in our study.

Search for comfort and ease of operation is ubiquitous throughout the world. All biomedical research directly or indirectly chooses that path for short term or long-term gain. Mercury rectal thermometers considered previously the gold standard are becoming obsolete because of ban on mercury use. Rectal thermometry itself is being considered hazardous for incidences of rectal perforation and introduction of infection. ${ }^{[13,14]}$ Rectal thermometry is not preferred as most of the time baby passes stool/meconium because of rectal stimulation. Moreover, baby needs to be exposed to extremes of temperature especially in resource poor developing countries where overall environmental temperature is not optimum for baby and newborns are well wrapped and especially mummified to prevent cold stress. Exposure of baby just for recording rectal temperature as routine is unwarranted, both by clinicians as well as parents and other caretakers. Baby also responds with discomfort and struggling and holding it in place requires continued discomfort to baby.[15] Axillary digital thermometry has replaced rectal mercury thermometry and is acceptable but it also needs unwrapping of baby and wiping of axilla, although the discomfort level is less, therefore the search for a better non-disturbing tool continues as temperature instability in newborns is a common phenomenon with both hypo and hyperthermia common. Global burden of neonatal hypothermia is estimated to be prevailing in range of $11-92 \%$ in home born and 32- 85\% in hospitals even in tropical countries. [16]

$21^{\text {st }}$ century has seen the entrance of new sites for measurement of temperature with Tympanic membranes thermometry by ear temperature and temporal artery thermometry by forehead temperatures. Comfort and ease of operation of newer techniques must be extended to newborn, as thermal care of newborn is a universally accepted part of essential newborn care, but different studies have shown varying results with these methods. Human neonate is a homoeothermic mammal and responds adaptively to changes in environment, but his capacity is limited. He is affected by environment quickly, both fall and rise in his temperature are fairly common. Tympanic membrane thermometers measure radiant heat from the tympanic membrane and nearby ear canal and display the absolute value (unadjusted mode) or a value automatically calculated from absolute reading on basis of nomograms relating to actual core temperature obtained in clinical studies (adjusted mode). These measurements are very convenient but may be more variable than directly determined oral or rectal values. Studies in adults show that readings are lower in with unadjusted mode than in adjusted mode. Studies in adults show that unadjusted mode tympanic membrane values are $1.6^{\circ} \mathrm{F}\left(0.8^{\circ} \mathrm{C}\right)$ lower than rectal temperatures. There is paucity of data for children especially so for newborns for these newer techniques.
Hypothermia is common in infants born at hospitals (prevalence range, $32 \%$ to $85 \%$ ) and homes (prevalence range, $11 \%$ to $92 \%$ ), even in tropical environments. Prevalence of newborn fever or hyperthermia used here interchangeably is reported to be as $20-40 \%$ depending upon the environmental conditions. ${ }^{[5,17]}$ infrared thermometers are third generation thermometers which have gained popularity just because of ease of operation and instantaneous results. It has come up as a promising tool but unfortunately it has not been recommended for use in newborns by manufactures. There are only few studies in newborns and that too with conflicting reports. ${ }^{[18,19]}$ and there is paucity of data from India especially from a hilly area like ours. In our study mean difference between Axillary digital and infrared forehead thermometer was obtained as 0.49 with level of agreement as -1.67 and +2.65 , suggesting that they do not agree well. Sethi et al from Gujrat India also compared axillary temperatures with infrared forehead temperatures and found poor agreement. They concluded that infrared forehead thermometer provides unsatisfactory accuracy which is similar to our results. ${ }^{[18]}$ Another study from Gujrat comparing noncontact forehead infrared thermometry with digital axillary thermometry in neonates reported mean difference of -0.56 and lower limit of agreement as -1.58 and upper limit of agreement as 0.46 and did not found it clinically acceptable.[20] They manually used $0.5 \mathrm{~cm}$ approximate distance from forehead, where as we used the contact with cover fixing the distance from skin contact avoiding any manual error as recommended by manufacturer, but they also concluded that infrared forehead thermometry cannot replace digital axillary thermometry, similar result as ours.

In our study the mean difference obtained between rectal mercury and infrared thermometer was as 0.15 with level of agreement as -2.09 and +2.40 again suggesting that they do not agree well and cannot be used interchangeably. A metaanalysis not confined to newborns but using data for paediatric patients using 30 articles between 2000-2019 in subjects $<18$ years of age recommended that temporal artery thermometry cannot be recommended for replacing rectal temperature measurement due to high proportion of false negative readings as it produced although they reported satisfactory accuracy, precision and specificity with acceptable lower and upper limits of agreement [21] Pierre $\mathrm{H}$ et al used cutaneous infrared thermometry for mass detection of febrile patients as a screening tool and found an excellent negative predictive value $(0.99)$ but poor positive predictive value (0.10) and did not recommend its use.[22]

Infrared forehead thermometry was widely accepted after the report of De Curis in 2008 from USA, suggesting infrared skin thermometer as a good alternative for newborns [6] as they found a good agreement. Duran R from Turkey in 2009 also found good agreement and recommended it as a useful and valid tool.[19] which are in contrast to our results. Sollai $S$ et al. assessed performance of a non-contact infrared thermometer in healthy newborns and found a satisfactory agreement with digital axillary temperature and recommended it as a promising tool.[23] which is also not according to our results. But we must remember that these are two different sites of human body for measurement of temperature although both are measuring human body temperature. In our study Pearson $r$ 
in both comparisons was found to be of 0.826 and 0.801 correlating it with axillary digital and mercury rectal also, both values being more than 0.7 suggesting a strong correlation. with inference that infrared forehead skin thermometry is a good alternative to digital axillary thermometry and mercury glass rectal thermometry keeping in mind that these are two different anatomical sites, one fully exposed and others well covered.

It is suggested that the need of hour is development of separate normative values for skin thermometry in relation to environmental temperature and humidity so that early detection and modification of environment may be done in developing world which lags behind drastically in providing comfortable thermoneutral zone of environmental temperature to newborn. This could be the reason for conflicting reports from developing and developed world. Changes in forehead skin temperature will be the earliest if environment is not suitable for baby and infrared forehead thermometers may thus provide future alternate use in newborns.

\section{CONCLUSIONS}

As the level of agreement of infrared forehead skin temperature with axillary digital and also with mercury rectal is poor, we conclude that it cannot be used interchangeably and is not recommended for measurement of core temperature of newborn. Body temperature differs at different sites. Rectal temperature measures temperature of an internal organ whereas axillary temperature measures least exposed area of body, while face or forehead temperature measures most exposed area of body which is largely affected by the microenvironment around body and it responds quickly to changes in environment. Strong Pearson correlation suggests that infrared forehead thermometry is a good tool and can be used in newborns for screening and early modification of environment for thermal comfort of baby with the purpose of providing baby a thermoneutral environment, while keeping in mind that it is not measuring the actual core temperature of body.

\section{REFERENCES}

[1] Singh M. Care of the Newborn. $8^{\text {th }}$ edn. New Delhi: CBS Publishers \& Distributors 2017: p. 257-66.

[2] National Neonatology Forum Teaching Aids: Newborn Care. http://www.newbornwhocc.org/pdf/teachingaids/hypothermia.pdf/Accessed April 20, 2018.

[3] WHO recommendations on Newborn health, Guidelines approved by the WHO guidelines review committee, updated

2017. apps.who.int/iris/bitstream/10665/259269/1/WHOMCA-17.07-eng.pdf (Accessed April 21, 2017).

[4] Maayan-Metzger A, Mazkereth R, Kuint J. Fever in healthy asymptomatic newborns during the first days of life. Arch Dis Child Fetal Neonatal Ed 2003;88(4):F312-4.
[5] Amadi HO, Olateju EK, Alabi P, et al. Neonatal hyperthermia and thermal stress in low and middle income countries: a hidden cause of death in extremely low birth weight neonates. Paediatr Int Child Health 2015;35(3):273-81.

[6] De Curtis M, Calzolari F, Marciano A, et al. Comparison between infrared skin thermometer good alternative for newborns. Arch Dis Child Fetal Neonatal Ed 2008;93(1):F55-7.

[7] Minamata Declaration 2013, UNEP Kumamaoto October 10 2013: United Nations treaty collection. Chapter - 17. https://treaties.un.org/doc/Publication/MTDSG/Volum e\%20II/Chapter\%20XXVII/XXVII-17.en.pdf Accessed on December 3, 2019.

[8] Cherry JD, Harrison JG, Kaplan SL. Feign and Cherry's Text book of Pediatric infectious diseases. $8^{\text {th }}$ edn. Philadelphia: Elsevier 2019: p. 52-6.

[9] Kasper DL, Hauser SL, Jameson JL, et al. Harrison's Principles of Internal Medicine. 19th edn. New York: McGraw-Hill Education 2015: p. 123-5.

[10] Gleason CA, Devaskar SU. Avery's Diseases of the newborn. $9^{\text {th }}$ edn. South Asia edition. Elsevier 2012: p. 357-66.

[11] Kliegman RM, Staton BF, GemeIII JWS, et al. Nelson Text Book of Pediatrics. 20 th edn (1 ${ }^{\text {st }}$ South Asian edn). Elsevier 2016:p. 1277-87.

[12] Agarwal R, Deorari A, Paul V, et al. AIIMS protocols in neonatology. $2^{\text {nd }}$ edn. Delhi: Noble 2019:p. 15-25.

[13] Di Paola I, Macneil P. Rectal thermometer complication. Anaesth Intensive Care 1985;13(4):441.

[14] Frank JD, Brown S. Thermometers and rectal perforations in the neonate. Arch Dis Child 1978;53(10):824-5.

[15] Roll C, Horsch S, Husing J, et al. Small premature infants do not tolerate axillary temperature measurement any better than rectal measurement. Study of the effect of axillary and rectal temperature measurement on vital parameters and cerebral hemodynamics and oxygenation. Z Geburtshife Neonatol 2000;204(5):193-7.

[16] Lunze K, Bloom DE, Jamison DT, et al. The global burden of neonatal hypothermia: systematic review of a major challenge for newborn survival. BMC Med 2013;11:24.

[17] 2010 Society of Hospital Medicine. Neonatal fever. J Hosp Med 2010;5(2) 23-4.

[18] Sethi A, Patel D, Nimbalkar A, et al. Comparison of forehead infrared thermometry with axillary digital thermometry in neonates. Indian Pediatrics 2013;50(12):1153-4.

[19] Duran R, Vatansever U, Acunas B, et al. Comparison of temporal artery, mid forehead skin and axillary temperature recordings in preterm infants $<1500 \mathrm{G}$ of birthweight. J Paediatr Child Health 2009;45(7-8):444-7.

[20] Patel AH, Patel MM, Bhavsar RH. Comparison of noncontact forehead thermometry with axillary digital thermometry in neonates. GCSMC J Med Sci 2016;5(1)20-4.

[21] Kiekkas P, Aretha D, Almpani F, et al. Temporal artery thermometry in pediatric patients: systematic review and meta-analysis. J Pediatr Nurs 2019;46:89-99. 
[22] Hausfater P, Zhao Y, Defrenne S, et al. Cutaneous infrared thermometry for detecting febrile patients. Emerg Infect Dis 2008;14(8):1255-8.
[23] Sollai S, Carlo D, Berti E, et al. Performance of a noncontact infrared thermometer in healthy newborns. BMJ Open 2016;6(3):e008695. 